\title{
Improvement of Physicochemical Properties of N-4472. Part III. VC/N-4472 Complex Formation and Self-association in Aqueous Solution
}

\author{
Koichi Iтон, ${ }^{*}, a, b$ Yuichi Tozuka, ${ }^{a}$ Toshio OGuchi, ${ }^{a}$ and Keiji Yamamoто ${ }^{a}$ \\ ${ }^{a}$ Graduate School of Pharmaceutical Sciences, Chiba University; 1-33 Yayoicho, Inage-ku, Chiba 263-8522, Japan: and \\ ${ }^{b}$ Nisshin Seifun Group Inc.; 1-25 Kanda-Nishiki-cho, Chiyoda-ku, Tokyo 101-8441, Japan. \\ Received August 2, 2002; accepted October 10, 2002
}

To improve the aqueous solubility of a poorly water-soluble drug, $N$-[2-(3,5-di-tert-butyl-4-hydroxyphenethyl)-4,6-difluorophenyl]- $N^{\prime}$-[4-( $N$-benzylpiperidyl)]urea $(\mathrm{N}-4472)$, organic acid/N-4472 evaporates were prepared by using succinic acid, L-tartaric acid, citric acid and L-ascorbic acid (VC). Among these evaporates, only the VC/N-4472 evaporate at a molar ratio of more than 2 (VC/N-4472) formed stable colloidal particles (with a mean particle size $\leq 100 \mathrm{~nm}$ ) in aqueous solution. In particular, the evaporate prepared at the molar ratio of $5(\mathrm{VC} / \mathrm{N}-4472)$ formed a clear solution comprising fine particles with a narrow particle size distribution of 8 $15 \mathrm{~nm}$. On the basis of surface tension measurement, zeta potential determination and static light scattering measurement, it was conceivable that both $\mathrm{N}-4472$ and $\mathrm{VC}$ contributed to the formation of a surface-active complex in aqueous solution, while the colloidal particles could be interpreted as the self-association product of these complexes. According to the findings on ${ }^{1} \mathrm{H}-\mathrm{NMR}$ and attenuated total reflectance Fourier transform infrared spectra, it was postulated that upon combining both components at a molar ratio of 2 (VC/N-4472), a $1: 1$ association complex of $\mathrm{N}-4472$ and $\mathrm{VC}$ was formed, whereas the higher order complexes were assumedly formed with use of a molar ratio of more than 2 (VC/N-4472). Furthermore, it was evidenced that all of these complexes were composed of amphiphilic structures comprising both hydrophobic N-4472 moiety and hydrophilic VC moiety, thereby properly accounting for surface-active property of these complexes.

Key words solubilization; L-ascorbic acid; complex; self-association; amphiphilic; colloidal particles

Formation of the counter-ion salt characteristic of higher dissociation constant is one of the promising procedures extensively employed to improve the aqueous solubility of ionic but poorly water-soluble drugs. ${ }^{1)}$ However, it has been reported that the crystal lattice energy varied even in the crystalline salts formed with the same drug depending on kinds of the applied counter ions, leading to different physicochemical properties in the solid state including apparent solubility and dissolution rate, eventually resulting in difference in the oral absorption rate. ${ }^{2)}$ From the comparison of the aqueous solubility of both nicardipine phosphate and nicardipine hydrochloride, Michael et al. reported that approximately 10 -fold difference in the solubility was observed between them due to successful solubilization of nicardipine phosphate attributable to self-association and micelle formation in the aqueous solution. ${ }^{3)}$ These findings suggest that difference of the applied counter ions remarkably affected not only the solubility of the salt but also solubilizing behaviors in the aqueous solution. As a consequence, selection of the most appropriate counter ion is significantly outweighed upon the salt formation.

Diphenylmethane derivatives as anti-histamine agents ${ }^{4}$ and phenothiazine derivatives as psychotropic agents ${ }^{5,6)}$ were solubilized due to intrinsic self-association in aqueous solution. These drugs had common characteristic that the molecules possessed amphiphilic structures comprising both hydrophilic and hydrophobic moieties.

$N$-[2-(3,5-Di-tert-butyl-4-hydroxyphenethyl)-4,6-difluorophenyl]- $N^{\prime}$-[4-( $N$-benzylpiperidyl)]urea (N-4472) is a newly developed drug having a lipid-lowering effect. With its aqueous solubility of less than $0.2 \mu \mathrm{g} / \mathrm{ml}$ (solubility in JP XIV 2nd fluid and distilled water at $37^{\circ} \mathrm{C}$ ), this drug has a drawback to be poorly absorbed after oral administration. In the present study, with an aim to improve the aqueous solubility of N-4472 (solubility in JP XIV 1st fluid at $37^{\circ} \mathrm{C}: 44 \mu \mathrm{g} / \mathrm{ml}$, $\mathrm{p} K_{\mathrm{a}}: 7.9$ ), we investigated aqueous solubilizing behavior and mechanism of the evaporates of $\mathrm{N}-4472$ which were prepared by addition of various organic acids. ${ }^{7,8}$

\section{Experimental}

Materials N-4472 and its analogues (Fig. 1) were synthesized by Nisshin Seifun Group Inc. (Japan). L-Ascorbic acid (VC), succinic acid, L-tartaric acid, and citric acid monohydrate were of reagent grade and purchased from Wako Pure Chemical Industries, Ltd. (Japan). Deuterium oxide $\left(\mathrm{D}_{2} \mathrm{O}\right.$, Aldrich Chemical Co. Inc., U.S.A.), methanol- $d_{4}\left(\mathrm{CD}_{3} \mathrm{OD}\right.$, Euriso-top, France), sodium trimethylsilylpropansulfonate (DSS, Aldrich Chemical Co. Inc., U.S.A.) and tetramethylsilane (TMS, Nacalai Tesque, Inc., Japan) were of NMR reagent grade and were used as received. All other chemicals used were of analytical reagent grade.

Preparation of Organic Acid/N-4472 Evaporate The samples of various molar ratios of organic acid to N-4472 (organic acid/N-4472 $=0.5-5$ ) were prepared where the amount of N-4472 loaded was kept constant of $100 \mathrm{mg}$. Each sample was dissolved in $0.5 \mathrm{ml}$ of methanol. The solution was evaporated under a vacuum on water bath at $60^{\circ} \mathrm{C}$. The solid mass obtained was further dried in a vacuum drier at $70^{\circ} \mathrm{C}$ for $2 \mathrm{~h}$.

Solubility Determination Each evaporate containing $100 \mathrm{mg}$ of N-4472 was dispersed into $5 \mathrm{ml}$ of distilled water. The dispersions in a test tube were shaken for $2 \mathrm{~h}$ at $150 \mathrm{stroke} / \mathrm{min}$ in a water bath thermostatted at $37^{\circ} \mathrm{C}$. The dispersions were filtered through a membrane filter $(0.2 \mu \mathrm{m}$, Whatman Inc., U.S.A.) and the filtered solutions were appropriately diluted with the HPLC mobile phase solution. The concentrations of N-4472 in the solution were determined by HPLC (LC-6A, Shimadzu Co., Japan). The mobile phase (acetonitrile/distilled water/phosphoric acid $(100: 100: 1, \mathrm{v} / \mathrm{v} / \mathrm{v}))$ was delivered at a flow rate of $1.0 \mathrm{ml} / \mathrm{min}$ through a L-Column ${ }^{\circledR}$ ODS $(4.6 \mathrm{~mm}$ I.D. $\times$ $15 \mathrm{~cm}$ : CERI, Japan) at $40^{\circ} \mathrm{C}$. The detection wavelength was $274 \mathrm{~nm}$.

Particle Size Analysis The volumetric particle size distribution for each colloidal solution containing N-4472 was determined by dynamic light scattering on a Microtrac ${ }^{\circledR}$ UPA (UPA 150, Nikkiso Co., Ltd., Japan).

Turbidity Measurement The turbidity for each colloidal solution containing N-4472 or N-4472 analogues was determined as the absorbance at $650 \mathrm{~nm}$ on an ultraviolet-visible spectrophotometer (UV-160, Shimadzu Co., Japan).

Surface Tension Measurement The VC/N-4472 evaporate (molar ratio $=5$ ) was dissolved in distilled water in the concentration range of the 
evaporate from $9 \mu \mathrm{g} / \mathrm{ml}$ to $90 \mathrm{mg} / \mathrm{ml}$. A surface tension for each aqueous solution at $25^{\circ} \mathrm{C}$ was determined using a surface tension equipment (DCAT 11, DataPhysics Instruments $\mathrm{GmbH}$, Germany) by the Wilhelmy plate method. Data were plotted as a function of the logarithm of the VC/N-4472 evaporate concentration. The surface tension for the colloidal solutions generated by dispersing the various $\mathrm{VC} / \mathrm{N}-4472$ evaporates (molar ratio $=2-5$ ) in distilled water (N-4472 concentration: $20 \mathrm{mg} / \mathrm{ml}$ ) were determined in the same manner.

Zeta Potential Measurement A zeta potential for each colloidal solution containing N-4472 was determined by using a ELS-8000 ${ }^{\circledR}$ (Otsuka Electronics Co., Ltd., Japan). Each sample was analyzed in triplicate.

${ }^{1}$ H-NMR Spectroscopy ${ }^{1}$ H-NMR spectrum for each specimen was measured at $24{ }^{\circ} \mathrm{C}$ on a JEOL JNM-LA400 spectrometer (JEOL Ltd., Japan) operating at $399.65 \mathrm{MHz}$ for proton in $\mathrm{D}_{2} \mathrm{O}$ or $\mathrm{CD}_{3} \mathrm{OD}$ solution. Measurement conditions were as follows: $90^{\circ}$ pulse width, $6.25 \mu \mathrm{s}$; relaxation delay, $2.9007 \mathrm{~s}$; scan, 16 times. Either TMS or DSS was used as an internal standard.

ATR-FTIR Spectroscopy Attenuated total reflectance Fourier transform infrared (ATR-FTIR) spectra of both the VC/N-4472 evaporate (molar ratio $=5$ ) micellar solution and $\mathrm{VC}$ aqueous solution containing same concentration of $\mathrm{VC}(30.5 \mathrm{mg} / \mathrm{ml})$ without $\mathrm{N}-4472$ were determined between 1800 and $1700 \mathrm{~cm}^{-1}$ on a FT/IR-480 Plus spectrometer (JASCO Corporation, Japan) which attached the ATR accessory with a horizontal diamond crystal prism. The background absorbance of water was previously determined to act as a reference, which can be automatically subtracted from the absorbance of specimen.

Static Light Scattering Measurement Static light scattering (SLS) measurement for each colloidal solution containing N-4472 was carried out using a DLS-7000 instrument (Otsuka Electronics Co., Ltd., Japan) equipped with a $10 \mathrm{~mW} \mathrm{He}-\mathrm{Ne}$ laser $(632.8 \mathrm{~nm})$. The refractive index increment $(\mathrm{d} n / \mathrm{d} c)$ for each colloidal solution was determined on a double beam differential refractometer, DRM-1021 (Otsuka Electronics Co., Ltd., Japan). The weight-average molecular weight $\left(M_{\mathrm{w}}\right)$ of each colloidal particle, which obtained by adding $\mathrm{VC} / \mathrm{N}-4472$ evaporate (molar ratio $=3-5$ ) to distilled water, was obtained from plots of $\left(K c / R_{\theta}\right) v s \cdot \sin ^{2}(\theta / 2)$ by the following relationship using the SLS data $\left(R_{\theta}\right)$, the concentration and the $K$ value calculated by $\mathrm{d} n / \mathrm{d} c$

$$
K c / R_{\theta}=1 / M_{\mathrm{w}}\left[1+\left\{16 \pi^{2} R_{\mathrm{g}}^{2} \sin ^{2}(\theta / 2)\right\} / 3 \lambda^{2}\right]
$$

where $K$ is an optical constant, $c$ is the concentration, $R_{\theta}$ is the Rayleigh ratio, $\theta$ is the scattering angle and $R_{\mathrm{g}}$ represents the radius of gyration. $\left.{ }^{9}\right)$

\section{Results and Discussion}

Formation of Colloidal Particles Containing N-4472 in Aqueous Solution With use of succinic acid, L-tartaric acid, VC and citric acid (Fig. 1), the evaporates being constituted of N-4472 and organic acids at various molar ratios (organic acid $/ \mathrm{N}-4472=0.5-5.0)$ were prepared according to the solvent method. To these evaporates, distilled water was added so that the $\mathrm{N}-4472$ concentration might become $20 \mathrm{mg} / \mathrm{ml}$. The resultant dispersions were shaken at $37^{\circ} \mathrm{C}$ for $2 \mathrm{~h}$ and then filtered through a membrane filter $(0.2 \mu \mathrm{m})$. The filtrates were subjected to the determination of $\mathrm{N}-4472$ concentrations. Figure 2 shows the N-4472 concentration profiles versus the molar ratios of organic acids (organic acid/N4472) for various evaporates. The $\mathrm{VC} / \mathrm{N}-4472$ evaporate showed specifically high concentration of N-4472 in the filtrate relative to those of other organic acid evaporates. Investigation of the $\mathrm{N}-4472$ concentration profiles versus the molar ratios of $\mathrm{VC}$ demonstrated that $\mathrm{N}-4472$ concentration began to sharply increase at a molar ratio of 1 , subsequently amounting to $20 \mathrm{mg} / \mathrm{ml}$ at molar ratios of $2-5$. On the other hand, in parallel with alterations of the molar ratios, the outer appearance of the solution changed from a turbid colloidal solution at a molar ratio of 2 to a transparent solution at a molar ratio of 5 . Figure 3 shows the absorbance at $650 \mathrm{~nm}$ of the colloidal solution and mean particle sizes of the colloidal particles at the molar ratios of $2-5$. With an increase of the

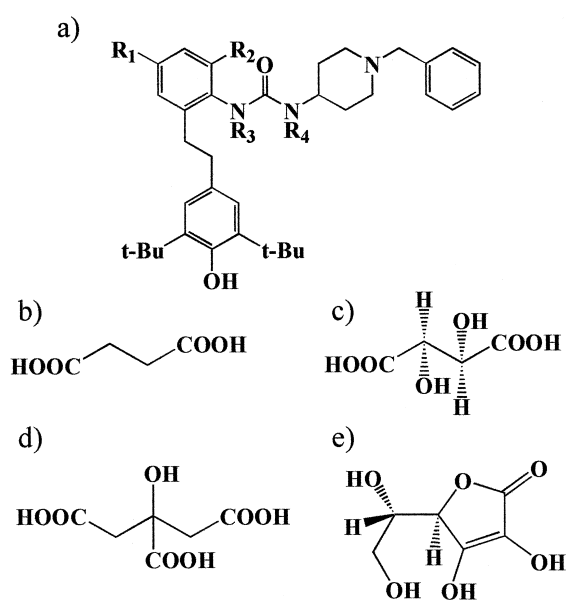

Fig. 1. Chemical Structures of N-4472, Its Analogues and Various Organic Acids

a) N-4472 $\left(\mathrm{R}_{1}=\mathrm{R}_{2}=\mathrm{F}, \mathrm{R}_{3}=\mathrm{R}_{4}=\mathrm{H}\right)$, analogue $\mathrm{A}\left(\mathrm{R}_{1}=\mathrm{R}_{2}=\mathrm{R}_{3}=\mathrm{R}_{4}=\mathrm{H}\right)$, analogue $\mathrm{B}$ $\left(R_{1}=R_{2}=R_{3}=H, R_{4}=M e\right)$, analogue $C\left(R_{1}=R_{2}=H, R_{3}=M e, R_{4}=H\right)$, analogue $D$ $\left(\mathrm{R}_{1}=\mathrm{R}_{2}=\mathrm{H}, \mathrm{R}_{3}=\mathrm{R}_{4}=\mathrm{Me}\right)$, b) succinic acid, c), L-tartaric acid, d) citric acid, e) L-ascorbic acid.

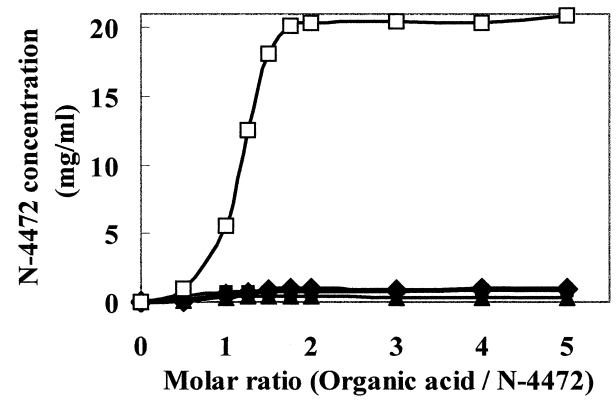

Fig. 2. Variation in the Amount of N-4472 Dissolved after Dispersing Various Organic Acid/N-4472 Evaporates into Distilled Water at $37^{\circ} \mathrm{C}$

$\longrightarrow$ - succinic acid/N-4472 evaporate; ———, L-tartaric acid/N-4472 evaporate; $-\mathbf{\Delta}-$, citric acid/N-4472 evaporate; — $\square$ - L-ascorbic acid/N-4472 evaporate.

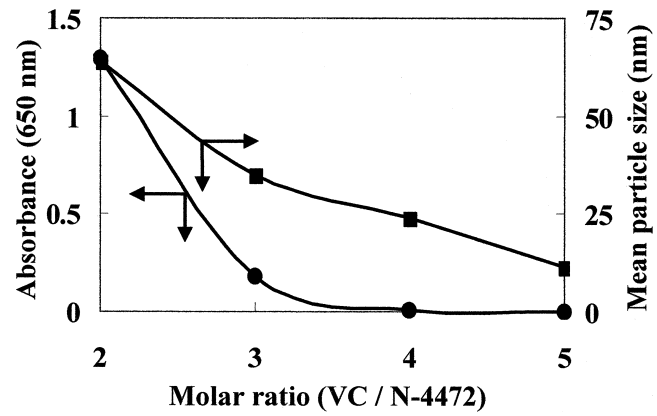

Fig. 3. Effect of Molar Ratio of VC/N-4472 on the Turbidity and Mean Particle Size of Colloidal Solution Formed by Dispersing the VC/N-4472 Evaporate into Distilled Water at $37^{\circ} \mathrm{C}$

Each colloidal solution contained $20 \mathrm{mg} / \mathrm{ml}$ of $\mathrm{N}-4472$. — - , turbidity (absorbance at $650 \mathrm{~nm}) ;-\mathbf{\square}-$, mean particle size.

molar ratio, both the turbidity and the mean particle size decreased. Particularly, the solution was transparent at the molar ratios of 4 and 5, with the mean particle sizes being $24 \mathrm{~nm}$ and $11 \mathrm{~nm}$, respectively. Therefore, it is confirmed that the $\mathrm{VC} / \mathrm{N}-4472$ evaporate forms very fine particles containing $\mathrm{N}-4472$ in its aqueous solution also that the particle sizes reduced and transparency of the solution increased with an 


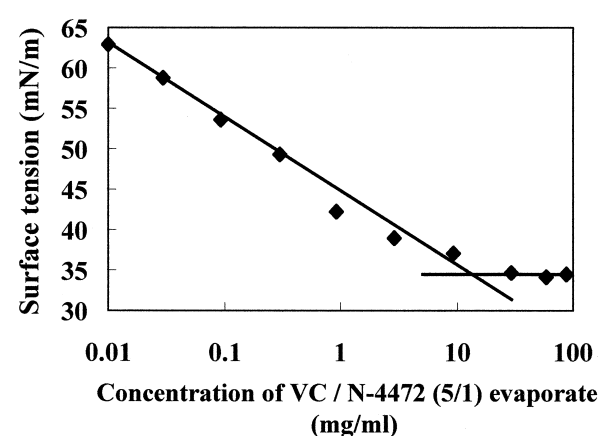

Fig. 4. Surface Tension of Dispersed Solution of VC/N-4472 (5/1) Evaporate into Distilled Water at $37^{\circ} \mathrm{C}$

Straight lines represent least-square fits.

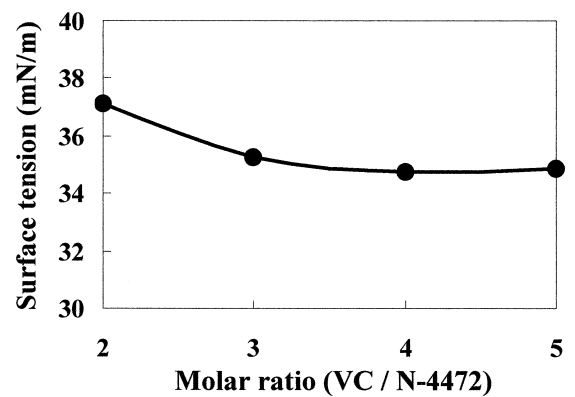

Fig. 5. Relationship between Surface Tension of Colloidal Solutions and Molar Ratio of VC/N-4472 when the Evaporate Was Dispersed into Distilled Water at $37^{\circ} \mathrm{C}$

Each colloidal solution contained $20 \mathrm{mg} / \mathrm{ml}$ of N-4472.

increase in molar ratios of $\mathrm{VC}$.

Characterization of Colloidal Particles Containing N4472 Shaking of the colloidal solution (N-4472 concentration: $20 \mathrm{mg} / \mathrm{ml}$ ) derived from the $\mathrm{VC} / \mathrm{N}-4472$ evaporate $($ molar ratio $=5)$ generated stable foam, indicating that this solution contained a certain substance having surface activity. The surface tension of colloidal solutions consisting of the $\mathrm{VC} / \mathrm{N}-4472$ evaporates (molar ratio $=5$ ) at various concentrations was determined. Figure 4 shows the concentration-surface tension profiles of the $\mathrm{VC} / \mathrm{N}-4472$ evaporates $($ molar ratio $=5)$. This demonstrates the characteristic profiles of surface-active substances, i.e., sharp decrease in surface tension with the increase of the concentration which was followed by constant surface tension after critical micelle concentration. Figure 5 shows the surface tension values on the various colloidal solutions (molar ratios $=2-5$ ) with the N4472 concentrations being adjusted to $20 \mathrm{mg} / \mathrm{ml}$. The surface tension of the colloidal solutions (molar ratios $=2-5$ ) was held constant at $35-37 \mathrm{mN} / \mathrm{m}$, indicating remarkably lower values compared with the value of distilled water alone (72 $\mathrm{mN} / \mathrm{m}$ ). These results disclose the facts that a certain surface-active substance was formed irrespective of any molar ratios. Since either N-4472 or VC was devoid of any surface activity in aqueous solution when they were used alone, the observed surface activity might be attributed to the surfaceactive complex formed between N-4472 and VC. It is well known that surface-active substances performed self-association in aqueous solution. ${ }^{10-14)}$ The fine particles generated from the $\mathrm{VC} / \mathrm{N}-4472$ evaporates (molar ratios $=2-5$ ) were considered to be the self-association product of the $\mathrm{VC} / \mathrm{N}-$

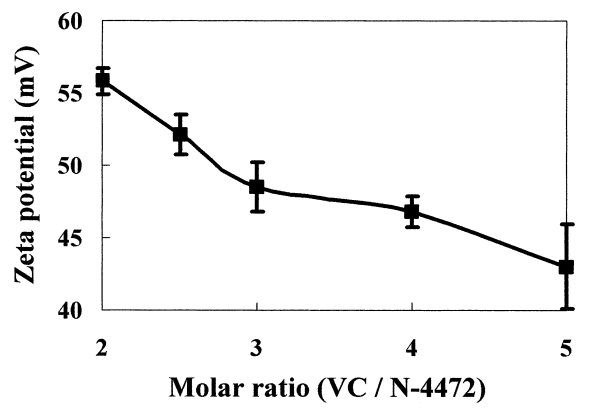

Fig. 6. Variation of Zeta Potential of Colloidal Solution as a Function of Molar Ratio of VC/N-4472 when the Evaporate Was Dispersed into Distilled Water at $37^{\circ} \mathrm{C}($ Mean \pm S.D. $)$

Each colloidal solution contained $20 \mathrm{mg} / \mathrm{ml}$ of $\mathrm{N}-4472$.

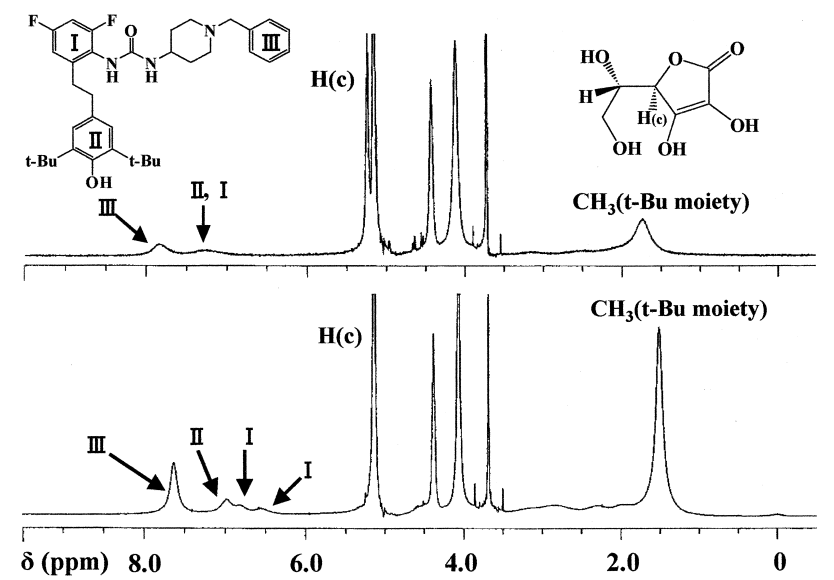

Fig. 7. Effect of Molar Ratio of VC/N-4472 Evaporates on Chemical Shifts of ${ }^{1} \mathrm{H}-\mathrm{NMR}$ Signals in Colloidal Solution

Top, ${ }^{1} \mathrm{H}-\mathrm{NMR}$ spectra of $\mathrm{VC} / \mathrm{N}-4472(2 / 1)$ evaporate in $\mathrm{D}_{2} \mathrm{O}$; bottom, ${ }^{1} \mathrm{H}-\mathrm{NMR}$ spectra of $\mathrm{VC} / \mathrm{N}-4472(5 / 1)$ evaporate in $\mathrm{D}_{2} \mathrm{O}$.

4472 complex intrinsically possessing surface activity.

It is postulated that decrease in the mean particle sizes in parallel with elevation of the molar ratios (VC/N-4472) observed in Fig. 3 might be attributable to alterations of the association numbers of the $\mathrm{VC} / \mathrm{N}-4472$ complex depending on the amount of $\mathrm{VC}$ added.

Figure 6 shows the zeta potential values on the colloidal solutions containing VC/N-4472 evaporates (molar ratios $=$ $2-5)$. The zeta potential values decreased from $+55 \mathrm{mV}$ to $+45 \mathrm{mV}$ in response to changes of the molar ratio from 2 to 5. Therefore, it is suggested that an increase in the molar ratio resulted in induction of the structural changes of the $\mathrm{VC} / \mathrm{N}-4472$ complex, leading to alterations of surface properties of colloidal particles.

Structure Elucidation of VC/N-4472 Complex Structural changes of the $\mathrm{VC} / \mathrm{N}-4472$ complex along with difference in molar ratios were investigated by ${ }^{1} \mathrm{H}-\mathrm{NMR}$ spectroscopy. Figure 7 shows ${ }^{1} \mathrm{H}-\mathrm{NMR}$ spectra of the colloidal $\mathrm{D}_{2} \mathrm{O}$ solutions containing $\mathrm{VC} / \mathrm{N}-4472$ evaporates (molar ratios $=2$ and 5). From the comparison of the chemical shifts of both protons on the aromatic ring (III) and $\mathrm{CH}_{3}$ protons in $t$ $\mathrm{Bu}$ group derived from N-4472, the upfield shift of the signals for the sample (molar ratio=5) were found by approximately $0.2 \mathrm{ppm}$ compared to those of low mixing ratio sample $($ molar ratio $=2)$. In addition, the signals attributable to 
Table 1. ${ }^{1} \mathrm{H}-\mathrm{NMR}$ Chemical Shifts of N-4472 and VC in the Free and VC/N-4472 Complex States

\begin{tabular}{|c|c|c|c|c|c|c|c|}
\hline & \multicolumn{7}{|c|}{ ppm } \\
\hline & & (I) & N-447 & $\begin{array}{l}\text { tic ring } \\
\text { (II) }\end{array}$ & (III) & $\mathrm{N}-4472 t-\mathrm{Bu} \mathrm{CH}_{3}$ & VC Lactone ring \\
\hline $\left.\mathrm{N}-4472^{a}\right)$ & 6.7 & & 6.8 & 6.9 & 7.3 & 1.4 & - \\
\hline $\mathrm{VC}^{b)}$ & - & & - & - & - & - & 4.8 \\
\hline VC/N-4472 (2/1) evaporate ${ }^{c)}$ & 7.2 & & 7.2 & 7.2 & 7.8 & 1.7 & 5.2 \\
\hline $\mathrm{VC} / \mathrm{N}-4472(5 / 1)$ evaporate ${ }^{c)}$ & 6.6 & & 6.8 & 7.0 & 7.6 & 1.5 & 5.1 \\
\hline
\end{tabular}

a) Chemical shift of $\mathrm{N}-4472$ signals in $\mathrm{CD}_{3} \mathrm{OD} / \mathrm{D}_{2} \mathrm{O}(2: 1)$ solution. b) Chemical shift of $\mathrm{VC}$ signal in $\mathrm{D}_{2} \mathrm{O}$. c) Chemical shift of $\mathrm{N}-4472$ and $\mathrm{VC}$ signals in $\mathrm{D}_{2} \mathrm{O}$.
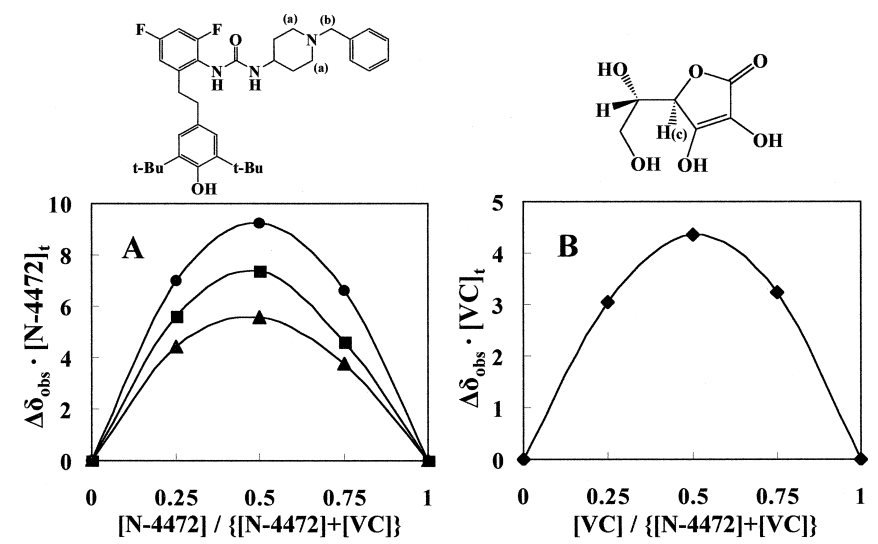

Fig. 8. Continuous Variation Plot (Job Plot) for Protons of N-4472 and of $\mathrm{VC}$

$\Delta \delta_{\text {obs }}$ represents the chemical shift difference between $\mathrm{N}-4472$ free form and the $\mathrm{VC} / \mathrm{N}-4472$ at each molar fraction. A: N-4472-0—; (a) $)_{\text {axial }},-\boldsymbol{\square}-\mathrm{H}(\mathrm{b}),-\boldsymbol{\Delta}-$; $\mathrm{H}(\mathrm{a})_{\text {equatorial. }}$ B: $\mathrm{VC} \longrightarrow$ - $\mathrm{H}(\mathrm{c})$.

protons on the aromatic rings (I) and (II) of N-4472, as well as proton $(\mathrm{H}(\mathrm{C}))$ bound to a lactone ring of $\mathrm{VC}$ in the sample $($ molar ratio $=5)$ were evidenced to shift upfield relative to those of the sample (molar ratio=2). Table 1 shows the chemical shifts of some protons of N-4472 and VC observed in N-4472, VC and VC/N-4472 evaporates solution. Since ${ }^{1} \mathrm{H}-\mathrm{NMR}$ signals of $\mathrm{N}-4472$ could not observe in $\mathrm{D}_{2} \mathrm{O}$ due to aqueous insolubility, the chemical shift of N-4472 alone was determined by using the mixture solution of $\mathrm{CD}_{3} \mathrm{OD}$ and $\mathrm{D}_{2} \mathrm{O}$ in consideration of the effect of $\mathrm{D}_{2} \mathrm{O}$. There was a difference in the chemical shifts of VC/N-4472 evaporates solution (molar ratio $=2$ and 5) compared with $\mathrm{N}-4472$ and VC solution alone. From these results, it was postulated that there were two kinds of complexes formed in the aqueous solution.

To assess the stoichiometric ratios of the VC/N-4472 complex, ${ }^{1} \mathrm{H}-\mathrm{NMR}$ spectra were investigated by using $\mathrm{CD}_{3} \mathrm{OD}$. Figure 8 shows Job plot which was derived from ${ }^{1} \mathrm{H}-\mathrm{NMR}$ chemical shifts at various molar fractions $(r)$ of both N-4472 and VC. On the basis of the findings that Job plot showed the maximum at $r=0.5$ for the protons $(\mathrm{a}, \mathrm{b}, \mathrm{c})$ attributed to both $\mathrm{N}-4472$ and VC, the stoichiometry of the VC/N-4472 complex formed in methanol was confirmed to be $1: 1$ molar ratio. When ${ }^{1} \mathrm{H}-\mathrm{NMR}$ chemical shifts were compared between the complex and N-4472 free base, more notable changes in the chemical shifts were evidenced on $\mathrm{H}(\mathrm{a})$ and $\mathrm{H}(\mathrm{b})$ which were neighboring to nitrogen atom on the piperidine ring. Accordingly, this indicates that the complex contained ionic pairs within the structure which were generated

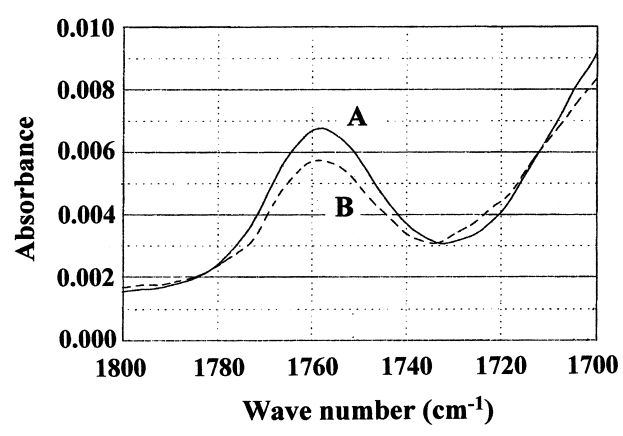

Fig. 9. Carbonyl Stretching Band of VC in ATR-FTIR Spectra for VC Aqueous Solution (A) and Micellar Solution (B) Generated from VC/N4472 (5/1) Evaporate

The VC aqueous solution (A) was prepared to become the same concentration as the $\mathrm{VC}$ concentration of micellar solution (B).

via electrostatic interaction between the nitrogen atom on the piperidine ring of $\mathrm{N}-4472$ and the enolic hydroxyl group of VC.

Ionic pair formation due to electrostatic interaction could occur even in aqueous solution in the similar manners as methanol solution, although the results obtained in the methanol solution cannot be directly extrapolated to the aqueous solution. In Fig. 2, formation of the colloidal particles containing $\mathrm{N}-4472$ began to sharply increase at the molar ratio of 1 , followed by completion of the colloidal particle formation including all the N-4472 molecules at the molar ratio of 2 . From this result, it was anticipated that the complex formed at a molar ratio of 2 in the aqueous solution would be a $1: 1$ ionic pair.

We attempted to clarify the structure of the complex formed at the molar ratio of 5, of which structure was presumably different from that of the complex having the stoichiometric ratio of $1: 1$. Figure 9 shows ATR-FTIR spectra of the micellar solution (molar ratio $=5$ ) and the $\mathrm{VC}$ aqueous solution ranging from 1800 to $1700 \mathrm{~cm}^{-1}$. Infrared absorption at $1758 \mathrm{~cm}^{-1}$ corresponding to the $\mathrm{C}=\mathrm{O}$ stretching of the VC was detected in the ATR-FTIR spectra in both of the solutions. However, the absorbance at $1758 \mathrm{~cm}^{-1}$ in the micellar solution (molar ratio $=5$ ) was significantly weaker than that in the $\mathrm{VC}$ aqueous solution, indicating that the carbonyl group in the VC might be involved in formation of this complex. To clarify more details of the interaction mode, investigation was performed with use of four kinds of the N-4472 analogues (A, B, C and D in Table 2). The VC/N-4472 analogues evaporates $($ molar ratio $=5)$ were prepared according to the solvent method, and distilled water was added to these evaporates. Turbidity for the resultant colloidal solution (con- 
Table 2. Turbidity of Colloidal Solutions Prepared by Dispersing VC/N4472 Ananogues (5/1) Evaporates into Distilled Water at $37^{\circ} \mathrm{C}$

\begin{tabular}{|c|c|c|c|c|c|}
\hline & $\mathrm{R}_{1}$ & $\mathrm{R}_{2}$ & $\mathrm{R}_{3}$ & $\mathrm{R}_{4}$ & Absorbance at $650 \mathrm{~nm}$ \\
\hline N-4472 & $\mathrm{F}$ & $\mathrm{F}$ & $\mathrm{H}$ & $\mathrm{H}$ & 0.000 \\
\hline A & $\mathrm{H}$ & $\mathrm{H}$ & $\mathrm{H}$ & $\mathrm{H}$ & 0.001 \\
\hline B & $\mathrm{H}$ & $\mathrm{H}$ & $\mathrm{H}$ & $\mathrm{Me}$ & 2.025 \\
\hline $\mathrm{C}$ & $\mathrm{H}$ & $\mathrm{H}$ & $\mathrm{Me}$ & $\mathrm{H}$ & 0.004 \\
\hline $\mathrm{D}$ & $\mathrm{H}$ & $\mathrm{H}$ & $\mathrm{Me}$ & $\mathrm{Me}$ & 2.037 \\
\hline
\end{tabular}

centration of the $\mathrm{N}-4472$ analogues $=20 \mathrm{mg} / \mathrm{ml}$ ) was determined. Table 2 shows the absorbance at $650 \mathrm{~nm}$ of the colloidal solutions containing N-4472 or four kinds of the analogues. Both the analogous compounds (A) and (C) formed transparent solution as was the same with $\mathrm{N}-4472$, whereas both the analogous compounds (B) and (D) occurred as white colloidal condition. In other words, only the analogues having hydrogen as the $\mathrm{R}_{4}$ substituent occurred as the transparent solution due to VC-induced solubilization, irrespective of $R_{3}$ substituent, suggesting that the hydrogen as the $R_{4}$ substituent might contribute to formation of the complex at the molar ratio of 5 .

It is conceivable that the $1: 1$ complex of N-4472 and VC generated by the electrostatic interaction at molar ratio of 2 might evolve into the higher order complex, namely different kind of VC/N-4472 complex formed at molar ratio of 5 via the further interaction of VC. The interaction mode and the responsible site in the higher order complex might reside on the hydrogen bond between the $\mathrm{NH}$ group bound to a piperidine ring of the urea moiety in N-4472 molecule and the carbonyl oxygen of VC. The interaction site responsible for the higher order complexation was considered to be specified as described above from the structural point of view, the stoichiometric ratio of the higher order complex was anticipated to be $1: 2$ of N-4472 and VC Furthermore, formation of amphiphilic structure comprising both hydrophilic VC moiety and hydrophobic N-4472 moiety within its molecule is conceivably responsible for the surface activity of the complex in aqueous solution.

Formation Mechanism of Colloidal Particles in Aqueous Solution From the static light scattering measurement, the weight-average molecular weight of each colloidal particle was able to determine using the plots of $\left(K c / R_{\theta}\right) v s$. $\sin ^{2}(\theta / 2)$ according to the Rayleigh-Debye equation. ${ }^{9)}$ Figure 10 shows the weight-average molecular weight of each particle in the colloidal solutions with molar ratios of $3-5$. The weight-average molecular weight of each particle in the micellar solution of the molar ratio of 5 was approximately 14000 , whereas the counterpart obtained at molar ratio of 3 was about 230 -fold greater than the former one. Since the weight-average molecular weight of the self-association product depended on the association number of the complex, the increase of VC amount might contribute to the remarkable decrease of association number. Schreier et al. reported

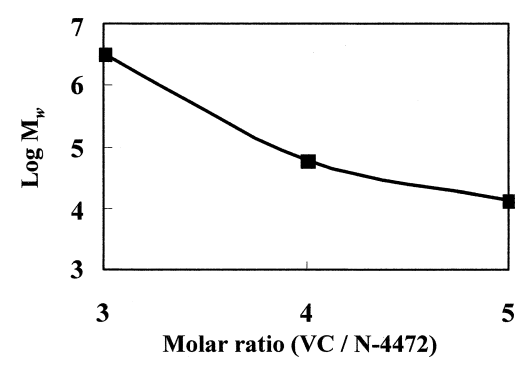

Fig. 10. Variation of Weight-Average Molecular Weight $\left(M_{\mathrm{w}}\right)$ of Colloidal Particles as a Function of Molar Ratio of VC/N-4472

that when drugs possessing surface activity formed the micelles following self-association in aqueous solution, the association number was as small as 10 , unlike those of surfactants $(50-200) .{ }^{15)}$ From the assumption that the micellar solution of the molar ratio of 5 was composed of the $1: 2$ complex of N-4472 and VC with the molecular weight of 930, the association number of the $1: 2$ complex was anticipated to be 15 from the weight-average molecular weight (14000), being consistent with the result reported by Schreier et al. Nostro et al. investigated the surface active properties of $\mathrm{VC}$ derivatives (ASC 8, ASC 10, ASC 12) which were C 8, C 10 and $\mathrm{C} 12$ esters of $\mathrm{VC}$, they reported that all $\mathrm{VC}$ derivatives had surface active properties which were due to their amphiphilic structure comprising both hydrophilic VC moiety and hydrophobic alkyl chain. ${ }^{16)}$ They also reported that ASC 8 with the shortest alkyl chain was freely soluble in water through micelle formation, whereas ASC 10 and ASC 12, the hydrophobic moiety consisting of longer alkyl chains, showed low aqueous solubility and no micelle formation. ${ }^{16)}$ These results could be attributable to the difference in the hydrophilic-hydrophobic balance (HLB) values of the amphiphilic VC derivatives. As shown in Fig. 3, the turbidity and the mean particle size were reduced in parallel with the increase in the molar ratio and finally the transparent solution was obtained at the molar ratios of 4 and 5. These phenomena could be explained by the subsequent interaction of $\mathrm{VC}$ with the initially formed $1: 1$ complex during the course of the VC molar ratio increment. Further the $1: 2$ complex of $\mathrm{N}-4472$ and VC should have high HLB value due to the increase of hydrophilic moiety in the complex, resulting in the small size associates in aqueous solution.

\section{Conclusion}

The evaporate prepared from N-4472 and VC showed a specific property to form colloidal particles in aqueous solution which size was less than $100 \mathrm{~nm}$. The resultant colloidal particles were found to be an association product which was generated by self-association of the amphiphilic VC/N-4472 complex which was initially formed in aqueous solution. The formed complex was composed of two different subtypes including the $1: 1$ complex at the low molar ratio of $\mathrm{VC} / \mathrm{N}-$ 4472, and the higher order complex produced by further interaction of $\mathrm{VC}$ and increment of the molar ratio. With increasing the molar ratio, concentration of the higher order complex increased, resulting in decrease in the mean particle size of the colloidal particles and in increase of the transparency of the colloidal solution, and finally culminating in $\mathrm{N}-4472$ being solubilized in aqueous solution. It was evi- 
denced that significant changes of the colloidal solution were attributed to both alterations of self-association due to formation of the amphiphilic VC/N-4472 complex and changes in its structure. Consequently, forming the surface-active complex between a drug and hydrophilic substance, which associated spontaneously to form micelle in aqueous solution seems to be useful for improving the aqueous solubility of poorly water-soluble drugs.

\section{References}

1) Stephen M. B., Lyle D. B., Donald C. M., J. Pharm. Sci., 66, 1-19 (1977).

2) Engel G. L., Farid N. A., Faul M. M., Richardson L. A., Winneroski L. L., Int. J. Pharmaceut., 198, 239-247 (2000).

3) Michael B. M., Susan M. R., Christopher A. K., Munir A. H., J. Pharm. Sci., 83, 1418-1420 (1994).

4) Attwood D., Adv. Colloid Interf. Sci., 55, 271-303 (1995).

5) Taboada P., Ruso J. M., Garcia M., Mosquera V., Colloids Surf. A Physicochem. Eng. Asp., 179, 125-128 (2001).
6) Tehrani S., Brandstater N., Saito Y. D., Dea P., Biophys. Chem., 94, 87-96 (2001).

7) Itoh K., Tozuka Y., Oguchi T., Yamamoto K., Int. J. Pharmaceut., 238, $153-160$ (2002).

8) Itoh K., Matsui S., Tozuka Y., Oguchi T., Yamamoto K., Int. J. Pharmaceut., 246, 75-83 (2002).

9) Heimer S., Tezak D., Adv. Colloid Interf. Sci., 98, 1-23 (2002).

10) Wang Z., Morris K. R., Chu B., J. Pharm. Sci., 84, 609-613 (1995).

11) Surakitbanharn Y., McCandless R., Krzyzaniak J. F., Dannenfelser R. M., Yalkowsky S. H., J. Pharm. Sci., 84, 720-723 (1995).

12) Yokoyama S., Fujino Y., Kondo M., Fujie T., Chem. Pharm. Bull., 43, 1055-1056 (1995).

13) Thibert R., Mach H., Clas S. D., Meisner D. R., Vadas E. B., Int. J. Pharmaceut., 134, 59-70 (1996).

14) Rades T., Muller-Goymann C. C., Int. J. Pharmaceut., 159, 215-222 (1997).

15) Schreier S., Malheiros S V. P., Paula E., Biochim. Biophys. Acta, 1508, $210-234$ (2000)

16) Nostro P. L., Capuzzi G., Pomani A., Mulinacci N., Langmuir, 16, $1744-1750$ (2000). 